\title{
Peer Counselor Training on Knowledge, Attitudes and Skills of Central Committee of Student Health Information and Reproductive Health Consultation (PIK-KRM)
}

\author{
Ririn Harini* and Henny Dwi Susanti \\ Department of Nursing, University of Muhammadiyah Malang, Indonesia \\ Jalan Bendungan Sutami No 188A Kota Malang, East Java 65145 \\ *Correspodning author: ri2nharini@gmail.com
}

\begin{abstract}
Background: The Indonesian Government, by the National Family Planning Board $(B K K B N)$, has followed up by monitoring and evaluating programs which is realized by providing technical guidance resilience in young people through Generation Planning program and developing Pusat Infomasi dan Konsultasi Remaja dan/atau Mahasiswa (PIK $\mathrm{KRR} / \mathrm{M})$. The solutions to improve the role of peer counselors are increasing the capacity of knowledge, attitudes, and skills through the training of peer counselors. Objective: To determine the effects of peer counselor training on knowledge, attitudes, and skills of PIKKRM board. Methods: The study was a Quasi - experiment with methods of pre-test and post-test nonequivalent control group. The sampling technique saturated Retrieval of data using questionnaires and observation checklist BKKBN guidelines already tested the validity and reliability. Results: the provision of training peer counselors have a significant influence ( significant) to the knowledge, attitudes and skills (post-test) board students PIK KRR/M. There is a difference scores of knowledge, attitude and skills of PIK $K R R / M$ board at the time of post-test, between control and treatment groups. Conclusion: Training peer counselors can improve knowledge, attitudes and skills of PIK KRR/M board in order to do the peer counseling about TRIAD KRR (Sexuality, HIV/AIDS, and Drugs).
\end{abstract}

Keywords: peer counselors, PIK-KRM board, reproductive health students.

\section{INTRODUCTION}

National Family Planning Coordinating Board or Badan Koordinasi Keluarga Berencana Nasional (BKKBN) 2010 states that one of the programs related to population is the Family Planning or Keluarga Berencana $(K B)$, which aims to control the population such as through the program Maturation Age of Marriage (PUP) which in its implementation has been integrated with the preparation of life for adolescents (PKBR) and is one of the main programs of national development contained in the Medium Term Development Plan (Development Plan 2010-2014). The direction of program policy of life for adolescents is to bring strong teenagers in order to be strong family to achieve a happy 
prosperous small family. Strong teenagers is building every teenager Indonesia became rigid that teenagers who delay marriage age, healthy behavior, avoiding the risk of TRIAD KRR (sexuality, HIV / AIDS and drug use), internalized the norm of happy prosperous small family and become an example, an idol, and a model for youth peer. Rigid teenager's framework refers from the evaluation program on Adolescent Reproductive Health or Kesehatan Reproduksi Remaja (KRR) in 1990-2000, conducted by the School of Public Health, University of Michigan, USA, in 2005 and evaluation of adolescent reproductive health in Asia, Africa and Latin America (World Bank Report, 2007).

The reality which is currently developing shows that adolescents have a very complex issue in line with the transition period experienced by adolescents. A prominent problem among adolescents are issues around TRIAD KRR (sexuality, HIV / AIDS and drugs), lack of knowledge of adolescents about reproductive health and women's median age at relatively low at 19.8 years (SDKI, 2007). Thus teenagers need assistance, guidance and serious measures to overcome the problems that they will be and already faces. According to the Policy Brief-Pusdu, 2012 that knowledge of adolescents on PUP through magazines, newspapers, radio is quite high while the information from Pusat Infomasi dan Konsultasi Remaja dan/atau Mahasiswa (PIK KRR/M) is still low.

Referring to the world program in the Millennium Development Goals (MDGs) about the importance of improving the status of adolescent reproductive health which is one of the priority to be handle at the moment, then the Center of Information and Consultation (PIK) is one of the organization that are developed in the GenRe program (Generasi Berencana), which is managed from, by and for Youth / Student in order to provide information and consultancy on the maturation age of marriage, eight of family functioning, TRIAD KRR (Sexuality, HIV and AIDS and drug use), life skills, gender and advocacy skills as well as communication, information and education. The existence and role of PIK R / M in the teen / college is very important in helping teens / college students to obtain information and services sufficient and correct consultation on setting up family life for teens / college students (BKKBN, 2012). In the course of consultation, information and education at the Center for Information and Consultation students are expected to make teens a healthy, creative, independent and having akhlaqul karimah in order to realize quality family also organizes outreach activities, research and reproductive health services teens about TRIAD KRR (Sexuality, drugs and HIV / AIDS) and to realize quality family with maturation age of marriage as well as aspire to realize the happy prosperous small families. (National Epidemiology Network, 2009). In an effort to improve understanding of adolescents on adolescent reproductive health makes tough in dealing with problems and were able to take the best decisions for themselves, then the indispensable consultation services for adolescents by consulting their peers referred to as Peer Educators (BKKBN, 2008).

Based on the results of interviews conducted by researchers with the Head of the Family Planning and Community Empowerment or Badan Keluarga Berencana dan Pemberdayaan Masyarakat (BKBPM) of Malang in July 2013 said that the implementation of the training of educators Peer carried out once a year by BKKBN center with the number of participants in these activities only two representatives from each PIK so that the number of Peer educators are still a few who get training. Total PIK in Malang, currently numbering 36 with the new status growing conditions there are 22, upright stages are 4 and rigid stages there are 10. Each PIK expected to have the initiative and support of the institution to carry out training for PIK administrators in improving the human resource of PIK officials so that it can become a professional Peer Educators independently. Preliminary study conducted by researchers at the PIK students in Malang of 10 students that are PIK administrators given a questionnaire said 5 people (50\%) say less confident in 
advising his friend, 3 people $(30 \%)$ said the lack of knowledge and information about reproductive health and the remaining 2 people (20\%) say that media for consulting is still very limited, for example leaflets, flipchart, modules, and much more. Whereas a counselor is expected to provide information on reproductive health and help provide alternative settlement of problems frequently encountered by their peers.

According to Aryani (2010) of adolescent knowledge before taking the PIK-KRR mostly low (60\%) and after following PIK-KRR is good (96.7\%). This shows that with the entrance in the center of information and consultation can affect adolescents in the search for sharing information with the caretaker of PIK in order to increase their knowledge and ability in advising on peers. So is the journal of "Peer" educators initiatives for adolescent reproductive health projects in Indonesia, Widiantoro (2004) that the approach to familycentered has been carried out on a pilot project carried out in Central Java and East Java to train peer educators, coordinated by the National Family Planning Board (BKKBN) to 80 peer educators who feel that such activities are important performed periodically, but the government cannot meet the comprehensive manner in all areas.

PIK KRM of Health Faculty University of Muhammadiyah Malang (Fikes UMM) is one of the Center for Information Consultation Students residing in the city of Malang under the auspices of BKBPM (Badan Keluarga Berencana dan Pemberdayaan Masyarakat) or Agency for Family Planning and Community Empowerment in Malang, which is still running and developing work programs and services actively in order to remain a PIK student the rigid phase. In his role as a center for health services hence the importance of Educators Peers can help overcome the issue of reproductive health to students or teenagers in general because of the impact if the teen does not know about reproductive health in the form of the malformed practice of health, the incidence of unwanted pregnancies, the incidence of HIV / AIDS and sexually transmitted disease (SDKIR, 2007).

The provision of information and education is a way to increase knowledge of adolescents about reproductive health so that at the end of 2015 at least 90 percent of teens are getting the information (ICPD and MDGs). This kind of activity has been carried out by the PIK KRM Fikes UMM, but there are some constraints experienced such lack of debriefing given to counselors on campus makes them less confident in providing health education to peers. Coordination activities such as visit frequency is not routinely implemented, health promotion activities according to the program is not working, the bustle of academic is high, so counselor's role can not be maximized.

Based on these problems can be seen that the knowledge, attitudes and skills must be owned by a teenager who entered the PIK-KRM, whereas how improved through positive activities that one through Peer Educators training to be known ability when carrying out its role in the school / campus and in the community in general. This has led the authors to conduct research on "The Influence of Peer Educators training on knowledge, attitudes and skills of the student board of Information and Consultation Center for Reproductive Health Students (PIK-KRM) in Fikes University of Muhammadiyah Malang.

\section{METHOD}

This study using Quasi-Experiment with methods of pretest and posttest nonequivalent control group. Quasi where the control group and the group given intervention is not chosen randomly. The intervention group was given training group with lectures, discussions, simulation / role play and giving the module while the control group is a group that is only given module only. 
The population in this study were students of the central committee of reproductive health information and consultation of students (PIK-KRM) in January to March 2014.

Samples determined by several criteria of inclusion PIK KRM member student who has never participated in the training, students who are active in PIK KRM, at least 3 months become a member of PIK KRM, willing to become respondents. Based on these criteria obtained 40 votes of each group,

Collecting data in this study include the identity of respondents filling in the form of age, gender and origin majors of study program. Measurement data in this study using questionnaires of knowledge and attitudes as well as a checklist of skills in the form of questions which refer to the guidelines by BKKBN training module (2008) about reproductive health and ARH / TRIAD KRR (sexuality, HIV / AIDS and drug use). As for the observers to make observations before and after the training conducted Peer Educators with special measuring devices observer. In this study, respondents were given another intervention by Peer Educators training with lectures, discussions, simulation/role play. Data collection was performed twice: pre-test and post-test where the break of data collection is one week.

Data analysis included univariate, bivariate and multivariate analysis. The bivariate analysis used was paired test, independent t-test and logistic linear regression.

\section{RESULTS AND DISCUSSION}

Based on the research that has been conducted on 80 students board of PIK-KRM showed that the characteristics of the sex of the student board of PIK-KRM respondents, the treatment group consist of 40 people, there are 30 people $(75 \%)$ female students, and the control group of 40 there are 26 people $(65 \%)$ female students. This suggests that women are more interested as the central committee of information and consultation with the reason many women who confide in their peers or sharing of personal problems than men. The departments of PIK-KRM respondents, the treatment group of 40 respondents who most of the department of nursing there are as many as 18 people (45\%), while the rest comes from other departments with a smaller percentage, as many as 8 people $(20 \%)$ come from the department of Pharmacy, as many as four people (10\%) came from Engineering, as many as 7 people (17.5\%) come from the department of Psychology and 3 (7.5\%) comes from the department of Social. Whereas in the control group, all respondents $(100 \%)$ from the study program of nursing science. Characteristics of age of the respondents in the experimental group the average age was 19 years and 6 months and the average age of the samples in the control group was 18 years and 3 months, indicating that respondents in this study more in the range between the ages of 18-19 years, where respondents by age 20 and 21 years had a smaller frequency.

\section{Comparison of knowledge, attitudes and skills of the student board of PIK-KRM between before and after the intervention were given training}

In the control group Based on testing of Table 7, it can be seen the correlation coefficient at the time of pre-test and post-test between knowledge score $(\mathrm{r}=0.611, \mathrm{p}=$ $0.000)$, attitude $(\mathrm{r}=0.900, \mathrm{p}=0.000)$, and skills $(\mathrm{r}=0.557, \mathrm{p}=0.000)$ has a significance value smaller than 0.05 alpha ( $\mathrm{p}<0.05$ ), so it can be concluded that there is a significant relationship between the scores of knowledge, attitude and skills of the student board of PIK-KRM between pre-test and post-test. The test results using a paired t test (paired sample $t$ test) to compare the scores of knowledge, attitude and skills of the student board of PIK-KRM between pre-test and post-test, showed that an increase in knowledge scores between pretest and posttest in control group. On average knowledge in the control group 
there was an increase of 1.22 points, an increase of average attitude 4.23 and the average skills of 0.42 between before and after training. The test results paired sample t test for comparison of the average scores of knowledge, attitude and skills of the student board of PIK-KRM between pre-test and post-test showed a significance value of $0.000(p<0.05)$ in Ho rejected, so that it can be concluded that there are significant differences in the average score of knowledge, attitude and skills of the student board of PIK-KRM between pre-test and post-test.

On treatment group (Group Training) based on testing of correlation coefficient values at the time of pre-test and post-test between knowledge score $(r=0.742, p=0.000)$, attitude $(\mathrm{r}=0.431, \mathrm{p}=0.006)$, and skills $(\mathrm{r}=0.433, \mathrm{p}=0.005)$ has a significance value smaller than alpha $0.05(\mathrm{p}<0.05)$, so it can be concluded that there is a significant relationship between the scores of knowledge, attitude and skills of the student board of PIK-KRM between pre-test and post-test, where the current post-test shows score relatively higher (indicated by a correlation coefficient that is positive) on the score of knowledge, attitude and skills than at pre-test. According to the table 10 shows that an increase in knowledge scores between pre-test and post-test in the treatment group that were given training. The mean increase in knowledge in the treatment group of 1.83, an increase in attitudes of 14.68 and skills of 1.82 between before and after training. Comparison of the average score of knowledge, attitude and skills of the student board of PIK-KRM between pre-test and post-test from the results of the $t$ test (paired sample $t$ test) showed a significance value of $0.000(\mathrm{p}<0.05)$, so that it can be concluded that there is a difference significantly on the average score of knowledge, attitude and skills of the student board of PIK-KRM between pre-test and post-test. Comparison of knowledge, attitudes and skills of the student board of PIK-KRM between the control group and the treatment group.

\section{Knowledge of student's board of PIK before and after Peer Educator Training}

According to the table 11 shows that the score of the student's knowledge PIKKRM board at the time of pre-test in the control group average of 13.28 and the treatment group average of 13.68. Furthermore, from the results of independent $t$ test showed significant value to score the knowledge of students board of PIK-KRM during the pretest, between the control group and the treatment group by $0.331(\mathrm{p}>0.05)$, which means that the score of the knowledge of students board of PIK-KRM during the pre-test, between the control group and the treatment group have no significant difference ( $p>0.05$, accept Ho). Scores of the knowledge of students board of PIK-KRM at the time of posttest in the control group average of 14.50 and the treatment group average of 16.35. Furthermore, from the results of independent $t$ test showed significant value to score the knowledge of students board of PIK-KRM in post test between the control group and the treatment group of 0.000 ( $\mathrm{p}<0.05$ ), which means that the score of the student's knowledge caretaker PIK-KRM during the post-test, between the control group and the treatment group was no significant difference $(\mathrm{p}<0.05$, reject Ho). Difference in knowledge score board PIK-KRM students in the control group average of 1.23 and the treatment group average of 2.68. Furthermore, from the results of independent $t$ test showed significant value for the difference of knowledge score of students caretaker PIK-KRM between the control group and the treatment group of $0.000(\mathrm{p}<0.05)$, which means that the difference of knowledge score of students caretaker PIK-KRM between the control group and the treatment group there is a significant difference $(\mathrm{p}<0.05$, reject Ho). 


\section{Attitude of Students Board of PIK before and after Peer Educator Training}

According to the table 12 shows that the attitude scores of the student board of PIK-KRM during pre-test is equally good in the control group or a treatment group of the average 50.7. Furthermore, from the results of independent $t$ test showed significant value to score student attitudes board PIK-KRM during the pre-test between the control group and the treatment group of $1.0(\mathrm{p}>0.05)$, which means that the score of the attitude of the student board of PIK-KRM during the pre-test, between the control group and the treatment group was no significant difference ( $p>0.05$, accept Ho). Attitude scores of student board of PIK-KRM at the time of post-test in the control group average of 54.93 and in the treatment group (by given training) by an average of 65.38. As for the difference in attitude score of student board of PIK-KRM in the control group average of 4.23 and in the treatment group average of 14.68. Results of independent t test showed significant value to score student attitudes board PIK-KRM during the post-test and the difference in scores between the control group and the treatment group was the same that is equal to 0.000 ( $\mathrm{p}<0.05$ ), which means that the score of the attitude of the student board of PIK$\mathrm{KRM}$ on when the post-test and the difference in scores between the control group and the treatment group was no significant difference $(\mathrm{p}<0.05$, reject Ho).

\section{Skills of Students board of PIK before and after Peer Educator Training}

According to the table 13 shows that the students' skills scores PIK-KRM board at the time of pre-test in the treatment group and the control group was equal at 4.63. Furthermore, from the results of independent $t$ test showed significant value to score skills during pre-test between the control group and the treatment group of 1.0 ( $p>0.05)$, which means that the skill's score of student board of PIK-KRM during the pre-test between the control group and the treatment group no significant difference ( $\mathrm{p}>0.05$, accept Ho). Scores of skills student board of PIK-KRM at the time of post-test in the control group average of 5.05 and in the treatment group average of 6.45. Furthermore, from the results of independent $t$ test showed significant value to skill's score of student board of PIK$\mathrm{KRM}$ in post test between the control group and the treatment group of 0.000 ( $\mathrm{p}<0.05$ ), which means that the score of student board of PIK-KRM during the post-test, between the control group and the treatment group was no significant difference ( $\mathrm{p}<0.05$, reject Ho). Difference score of student board of PIK-KRM in the control group average of 0.43 and in the treatment group average of 1.83. Furthermore, from the results of independent t test showed significant value for the difference in skill's score of student board of PIK-KRM between the control group and the treatment group of $0.000(p<0.05)$, which means that the difference in skill's score of student board of PIK-KRM between the control group and the treatment group there is a significant difference ( $\mathrm{p}<0.05$, reject Ho).

\section{The Effect Of Peer Educator Training to Knowledge, Attitudes and Skills of Student Board of PIK-KRM}

Results of linear regression in Table 17 on the effect of giving Peer educators training to knowledge, attitudes and skills (post-test) to Student Board of PIK-KRM shows the significance value of $0.000(\mathrm{p}<0.05)$, so it can be concluded that administration of Peer educators training give a significant influence towards the knowledge, attitudes and skills (post-test) to Student Board of PIK-KRM. The influence of Peer educators training can be known from the value of $\mathrm{R}$ square, where the greatest influence on The Peer Educators training to score attitudes (post-test) that is equal to $0.432(43.2 \%)$, while $56.8 \%$ are influenced by factors other than the provision of Peer Educators Training. Equation 
model for knowledge, attitudes and skills (post) to the results obtained training that is Knowledge $($ post $)=12.650+1.85$ Training, Attitudes $($ post $)=44.475+10.45$ Training, and skills (post) $=3.65+1.40$ Training, can be mean that without considering the effect of giving Peer educators training, then the knowledge, attitudes and skills scores (post) will remain constant increase (due to the constant coefficient is positive). However, when considering the effect of giving Peer educators training, it will be able to increase the knowledge, attitudes and skills scores (post) significantly since the coefficient is positive. The conclusion is the giving of Peer educators training can influence the increase in knowledge, attitudes and skills scores (post).

Table 1. The relationship between pre-test and post-test in Control Group

\begin{tabular}{lll}
\hline Variables & Correlation coefficient & $\mathrm{P}$ \\
\hline Knowledge & 0.611 & 0.000 \\
Attitude & 0.900 & 0.000 \\
Skills & 0.557 & 0.000 \\
\hline
\end{tabular}

Table 2. Comparison Result of Knowledge, Attitudes and Skills between the average pre-test and post-test in Control Group

\begin{tabular}{lrlrlc}
\hline & \multicolumn{4}{c}{ The control group } & \\
\multicolumn{1}{c}{ Pre test } & $\underline{\text { Post test }}$ & $\begin{array}{c}\text { The p-value of a } \\
\text { Variables }\end{array}$ \\
Mean & $\pm \mathrm{SD}$ & Mean & $\pm \mathrm{SD}$ & paired sample t test \\
\hline Knowledge & 13.28 & \pm 1.84 & 14.50 & \pm 1.59 & 0.000 \\
Attitude & 50.70 & \pm 6.64 & 54.93 & \pm 7.80 & 0.000 \\
Skills & 4.63 & \pm 1.66 & 5.05 & \pm 1.77 & 0.000 \\
\hline
\end{tabular}

Table 3. Correlation between pre-test and post-test in Treatment Group

\begin{tabular}{lcc}
\hline \multicolumn{1}{c}{ Variables } & Correlation coefficient & $\mathrm{P}$ \\
\hline Knowledge & 0.742 & 0.000 \\
Attitude & 0.431 & 0.006 \\
Skills & 0.433 & 0.005 \\
\hline
\end{tabular}

Table 4. Comparison Results of Knowledge, Attitudes and Skills between the average pre-test and post-test in Treatment Group

\begin{tabular}{lrlrlc}
\hline & \multicolumn{4}{c}{ Evaluation of treatment group } & \\
\multicolumn{1}{c}{ Pre test } & \multicolumn{2}{c}{ Post test } & The p-value of a \\
Variables & Mean & $\pm \mathrm{SD}$ & Mean & $\pm \mathrm{SD}$ & paired sample t test \\
\hline Knowledge & 13.68 & \pm 1.82 & 16.35 & \pm 1.63 & 0.000 \\
Attitude & 50.70 & \pm 6.64 & 65.38 & \pm 3.57 & 0.000 \\
Skills & 4.63 & \pm 1.66 & 6.45 & \pm 1.06 & 0.000 \\
\hline
\end{tabular}


Table 5. Comparison Results of Knowledge Scores of Students Board of PIK-KRM between control group and treatment group

\begin{tabular}{|c|c|c|c|c|c|}
\hline \multirow[b]{3}{*}{ Variables } & \multicolumn{4}{|c|}{ Evaluation } & \multirow{3}{*}{$\begin{array}{c}\text { The } p \text {-value of } \\
\text { independent sample } \\
\text { t test }\end{array}$} \\
\hline & \multicolumn{2}{|c|}{ Control } & \multicolumn{2}{|c|}{$\underline{\text { Treatment }}$} & \\
\hline & mean & $\pm \mathrm{SD}$ & mean & $\pm \mathrm{SD}$ & \\
\hline Pre test & 13.28 & \pm 1.84 & 13.68 & \pm 1.82 & 0.331 \\
\hline Post test & 14.50 & $\pm 1: 59$ & 16.35 & \pm 1.63 & 0.000 \\
\hline Difference score & 1.23 & $\pm 1: 53$ & 2.68 & \pm 1.25 & 0.000 \\
\hline
\end{tabular}

Table 6. Comparison Results of Attitude Scores of Students Board of PIK-KRM board between control and treatment groups

\begin{tabular}{lrlccc}
\hline & \multicolumn{4}{c}{ Evaluation } & The p-value of \\
& \multicolumn{2}{c}{ Control } & \multicolumn{2}{c}{ Treatment } & independent sample \\
\cline { 2 - 5 } \multicolumn{1}{c}{ variables } & mean & $\pm \mathrm{SD}$ & mean & $\pm \mathrm{SD}$ & $\mathrm{t}$ test \\
\hline pre test & 50.70 & \pm 6.64 & 50.70 & \pm 6.64 & 1.0 \\
Post test & 54.93 & \pm 7.80 & 65.38 & \pm 3.57 & 0.000 \\
Difference score & 4.23 & $\pm 3: 42$ & 14.68 & \pm 6.04 & 0.000 \\
& & & & & \\
\hline
\end{tabular}

Table 7. Comparison Results of Skills Scores of Students Board of PIK-KRM board between control and treatment groups

\begin{tabular}{lccccc}
\hline & \multicolumn{4}{c}{ Evaluation } & The p-value of \\
& \multicolumn{2}{c}{ Control } & \multicolumn{2}{c}{ Treatment } & independent sample \\
\cline { 2 - 5 } \multicolumn{1}{c}{ variables } & mean & $\pm \mathrm{SD}$ & mean & $\pm \mathrm{SD}$ & t test \\
\hline Pre test & 4.63 & \pm 1.66 & 4.63 & \pm 1.66 & 1.0 \\
Post test & 5.05 & \pm 1.77 & 6.45 & \pm 1.06 & 0.000 \\
Difference score & 0.43 & \pm 1.62 & 1.83 & \pm 1.53 & 0.000 \\
\hline
\end{tabular}

Table 8. Linear Regression Test Results

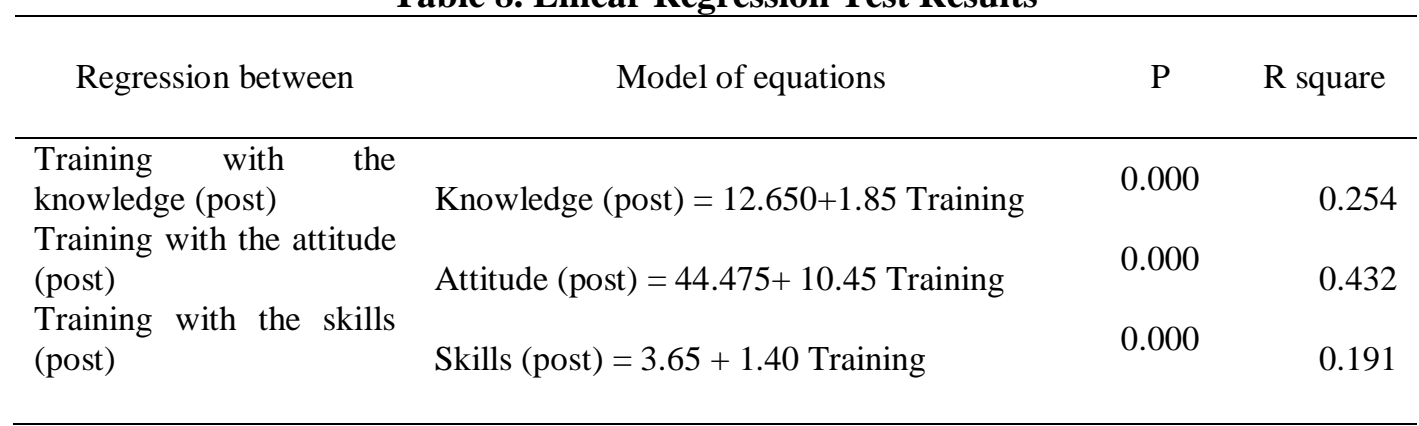

Results of research on knowledge of students board of PIK-KRM before and after the training showed that at the time of the pre-test knowledge of the respondents indicated that the current knowledge of pre-test between the treatment group and the control group was not much different, but after the post-test in the treatment group obtained average knowledge before and after treatment showed a significant increase $(\mathrm{p}<0.05)$, whereas in the control group also increased though it is small. The test results show that the difference in the value of knowledge of the effect of the intervention in the treatment groups by providing Peer Educators training ranging from lectures, discussion, role play and case 
studies showing an increase in the average value of significance $(p=0.00)$. The average value of knowledge in the treatment group (who have been given training intervention) increased by 1.83 point, while the control group difference in their mean value of 1.22 points. Both groups were equally increased although the treatment group there was an increase in the higher grades. Improved knowledge of the treatment group is caused due to the intervention of training have been given but it is also the knowledge that has been owned by the respondent before either gained from the experience of reading literature, electronic media and personal experience and sharing with peers so that they can recall training materials that have been studied previous. This is in accordance with the opinion of Simon Morton et al. (1995) suggested that knowledge is the result of stimulation of the information that be noted and remembered. Sarwono (2004) also found that information had been given to approach interpersonal communication / counseling on reproductive health will improve one's knowledge. The results of the Mevsim et al (2008) states that coach of peers by training method that used is able to transform knowledge during the training session well with peers about reproductive health.

The attitudes of students board of PIK-KRM before and after training according to the results showed that at the time of pre-test the attitude of the respondents indicated that the current attitude of the pre-test between the treatment group and the control group is the same that with a mean of 50.70 but after the post-test in the treatment group gained a mean attitude after intervention showed a significant increase $(\mathrm{p}<0.05)$, whereas the control group the increase is smaller than the treatment group. The test results show that the difference in the value of the attitude of the intervention effect in the group treated with Peer Educators training ranging from lectures, discussion, role play and case studies showing an increase in the average value of significance $(p=0.00)$. The average value of the attitude that has been given a training intervention had increased by 14.6 points, while the control group difference in their mean score of 4.23 points. Comparison of attitude scores between control group and treatment group in the post test of 0.000 ( $p<0.05$ ), which means that Ho is rejected with the conclusion that there is a significant difference (significant) attitude scores between the control group and the treatment group. The above results indicate that the attitude of a person it has previously obtained from the independent study, experience sharing the results even socialize with peers. The importance of the role of peers, the development of a positive peer environment is an effective way that can be taken to support the development of adolescents. In relation to the profit teens have positive peer groups, Laursen (2005) in Santrock (2012) suggest that positive peer groups allow teens to feel welcome and allow teens to test the new values and new insights. Further Laursen insists that positive peer groups provide an opportunity for teens to help others, and encourage teens to develop a network to give each other positive encouragement. Interaction among peers can be used to establish the meaning and perceptions and new solutions. Positive peer culture provides an opportunity for teens to test the effectiveness of communication, behavior, perceptions, and values that they have. (Santrock, 2012). Positive peer culture greatly help young people to understand that he is not alone in facing challenges. Positive peer culture that can be used to help change behavior and values of adolescents (Laursen, 2005). One effort that can be done to build a positive peer culture is to develop peer counseling in the teen community. Based on the opinion of several experts, we can conclude that the increase in scores attitudes greater in the treatment group can be influenced by the methods that have been used in the training were appropriate. Kirkpatrick (1994) said that for the success of the training needs to be taken into the appropriate method in accordance with the needs of the participants, the method is said to be proper if there is a positive change to the trainees. Improvement scores well on knowledge, attitudes and skills in the intervention group indicates that the 
methods used in this training can improve knowledge, attitudes and skills about reproductive health and TRIAD KRR (sexuality, HIV / AIDS and drugs) in conducting counseling on their peers. It also proves that the respondents were able to absorb the material that has been given at the time of the intervention. Additionally teenagers need to master the techniques of good communication so that the communication materials need to be given prior to the other training materials. This is in accordance with Suwarjo (2008), that the prospective Peer Educators should be given the ability to build interpersonal communication as well. Attitudes and basic counseling skills that include the ability to empathize, ability to attending, questioning skills, skills of summarizing the talks, assertiveness, genuineness, confrontation, and problem solving skills, are the abilities that given in the training of Peer Educators.

According to Azwar (1995) in Gordon (1935), that attitude is a kind of readiness to react to an object in a certain way. It can be said that readiness which meant a potential tendency to react a certain way when individuals are faced with a stimulus that calls for a response. Based on the above results that the small increase in the control group could occur because previously they already have experience in counseling on a peer in nature, but because they do not get the training more precisely how the correct application as a Peer educators so that a score attitudes cannot be improved significantly.

The skills of students board of PIK-KRM committee before and after shows that the average score during the pre-test to the treatment group and the control group is the same that is equal to 4.62 but after the post-test in the treatment group gained an average skill after intervention showed a significant increase $(\mathrm{p}<0.05)$, whereas in the control group also increased albeit small. The test results show that the difference in value of the skills intervention effect in the group treated with Peer Educators training on the correct techniques in counseling showed an increase in the average value of significance $(\mathrm{p}=$ $0.00)$. The average value of the knowledge that had been given training interventions increased by 1.83 point, while the control group difference in their mean score of 0.43 points. Differences in the average skill difference between the treatment groups was 1.40 points kotrol with a $\mathrm{P}$ value $<0.05$ means that there are significant differences in the average score of skills between pre-test and post-test.

According to these results could be explained that the skills of a person it is not easy to be changed as quickly as possible without going through a long process and continuously. That revelation in accordance with Winkel (2004) that stated if changes as a result of learning that will last a long time, even to a certain extent will not disappear again. Ability acquired will be privately owned and will not be erased. The results are relatively constant learning and scar. On motor skills, each learning activity will result in a positive change. The more often the person is doing and repeat the skill the more skilled. The results of study in the field of psychomotor and attitudes are also not easily forgotten, because the skills and attitudes once formed tend to hang on, even became stronger and began a stack of activities that no longer have a high awareness levels. Based on research conducted by Lestari, Wuri (2010) can be concluded that the training DDTK (Deteksi Dini Tumbuh Kembang) or Early Detection of Growth conducted three-day immersion effectively improve the knowledge, attitude and skills of the midwives who received intervention in the early detection of growth and development in children. It shows that the longer a person receiving training and learning up to action with the proper method it will show the maximum results as expected.

This study tried to see the treatment effect of training on score changes of knowledge, attitudes and skills. Measurements were carried out is to look at the results after the intervention (post-test). Measurements in this way is intended to see how big the influence of the Peer Educators training interventions to increase knowledge, attitudes and 
skills of students board of PIK-KRM. Score of post test is used to see how much the respondent can absorb the training materials provided during the intervention. Based on regression analysis of the effect of Peer educators training to knowledge, attitudes and skills (post-test) of students board of PIK-KRM shows the significance value of 0.000 (p $<0.05$ ), so it can be concluded that administration of Peer educators training gives a significant influence (significant) towards the knowledge, attitudes and skills (post-test) of students board of PIK-KRM. The influence of administration of Peer educators training can be known from the value of $\mathrm{R}$ square, where the greatest influence on the awarding of Peer Educators training is the effect of Peer educator training to attitudes score (post-test) that is equal to $0.432(43.2 \%)$, while $56.8 \%$ are influenced by factors other than the provision of Peer Educators Training.

Kirkpatrick (1994) said that for the success of the training needs to be taken into the appropriate method in accordance with the needs of the participants, the method is said to be proper if there is a positive change to the trainees. Improvement scores well on knowledge, attitudes and skills in the intervention group indicates that the methods used in this training can improve knowledge, attitudes and skills about reproductive health and TRIAD KRR (sexuality, HIV / AIDS and drugs) in conducting counseling on their peers. It also proves that the respondents were able to absorb the material that has been given at the time of the intervention. In the control group the increase always occurs in both the score of knowledge, attitude and skills in spite of little value. This shows that even though they do not preceive training on becoming a peer educator but armed with the knowledge and previous experience as coaching early entry as a trustee of PIK-KRM, the book from $\mathrm{BKKBN}$, sharing with friends, television and many others were still able to increase the score in the domain of knowledge, attitude and skills of the student board of PIK-KRM. Possible improvement that occurred in the control group occurred because in this group get stimulus from the questionnaires and the statements given by the researchers in addition to the training modules which eventually becomes a learning process in themselves. Another factor affecting the increased knowledge and skills in the control group is the work experience and the mass media. According to WHO (Notoatmodjo, 2007), a person's knowledge of an object can change and evolve according to the capabilities, needs and experiences of the objects in the environment. In addition, the control group likely has had the experience of reproductive health counseling and intervention before though not given their knowledge and skills training is still good.

Training can improve knowledge, attitude and skills of a person in a specific field. Results of research conducted by Willets (2003) showed that effective training programs enhance the knowledge and skills of employees, a similar study was done by Shefferet al (2009), the results indicate that the training undertaken to the 1286 health workers for 1 hour intervention effectively increase participants knowledge and changing attitudes became more positive, the same was found in research conducted by Law et al. (2007), the results showed a significant increase in the score of knowledge and skills between the before and after training on midwife training.

Improved training scores, scores attitudes and skills score higher in the treatment group compared with the control group, this is due to the treatment group participants are actively involved in the training. Learning methods are used in training are lectures, question and answer, group discussions and role play with fellow participants and practice with peers. It causes the participants interested and not bored so that it can understand the material well. Moreover presenters who host the activity is trainer of BKKBN who are competent in their field and have extensive experience in the training event package as attractive as possible. It is also in accordance with the opinion and Gaffikin Sullivan 
(1997), that the effectiveness of clinical training pressures in the application of knowledge in skills performance.

\section{CONCLUSIONS}

Based on the research results can be concluded that: Peer Educator Training can improve knowledge, attitude and skills of the student board of Information and Consultation Center for Reproductive Health of Students (PIK-KRM) in conducting counseling on peers about TRIAD KRR (Sexuality, HIV / AIDS and drugs) with a significance value of $0.000<0,05$. The average of student knowledge PIK KRM before and after the training is increasing by 1.83 points, attitudes by 14.68 points, and skills by 1.82 points.

Organizing regular training and sustainable so that it can continue to improve the knowledge, attitudes and skills of the management of Information and Consultation Center for Reproductive Health of Students or Pusat Informasi dan Konsultasi Kesehatan Reproduksi Mahasiswa (PIK-KRM) so that it can provide better service.

\section{REFERENCES}

Agampodi et al, (2008). Adolescents Information and Consultation Center for Reproductive Health Students Information and Consultation Center for Reproductive Health Students perception of reproductive health care services in Sri Lanka. Elsefier J

Ajzen, I. (2006). Theory and planned behavior. Available from: http://people.umass.edu/ajzen/tpb.html.

MOH and Development Agency, (2009). Counseling service guidelines Reproductive Health and Sexuality for students. National Epidemiology Network, Jakarta.

BKKBN, (2006). Counseling Workshop Module Adolescent Reproductive Health for Peer Educators candidate. The Directorate of Youth and Protection of Reproductive Rights, Jakarta.

BKKBN, (2008). The training module on adolescent reproductive health counseling for prospective Peer Educators. The Directorate of Youth and Protection of Reproductive Rights, BKKBN.

Ministry of Health, (2006). Training Needs Assessment Handbook. Employee Training and Education Center, Jakarta.

Djamarah, SB, 2006. Teaching and Learning Strategies. Rineka copyright, Jakarta.

Green, L., Kreuter, MW (2003). Ducation Health Planning, a diagnostic approach, second. ed. Mayfield Publising Company, California.

Hull, TH, Hasmi, E., Widyantoro, N., 2004. "Peer" educators initiatives for adolescent reproductive health projects in Indonesia. Reprod. Health Matters 12, 29-39.

Lestari, W, (2010). Thesis Postgraduate Gadjah Mada University. Effect of early detection of developmental training to increase the knowledge, attitudes and skills of midwives in Banjar district. Etc. Gadjah Mada.

Mevsim, V., Guldal, D., Ozcakar, N., Saygin, O., (2008). What was retained? The assessment of the training for the peer trainers' course on short and long term basis. BMC Public Health 8, 24.

Michielsen, K., Beauclair, R., Delva, W., ROELENS, K., Van Rossem, R., Temmerman, M., (2012). Effectiveness of a peer-led HIV prevention intervention in secondary schools in Rwanda: results from a non-randomized controlled trial. BMC Public Health 12, 729. 
Moeliono, (2010). Active learning process: Communication, Information, Education and Communication (IEC) adolescent reproductive health for children aged 11-15 years. Jakarta.

Nurapni, Aryani, (2010). PIK-KRR effectiveness to the improvement of adolescent reproductive health knowledge in a private high school Al-Wasliyah I Medan. Kesehat science. Mobi. Etc. Gadjah Mada.

Rustiningsih, (2003). Little doctors with recitation and lecture method of question and answer in the district of Sukoharjo Kab.Sukoharjo. Thesis Post Sarj. University of Gadjah Mada

Santrock, JW, (2012). Educational Psychology. Humanika Salemba, Jakarta.

Simons, BG, Morton. (2008). Introduction to Health Education and Health Promotion. Waveland Press, Inc., Illinois.

Suwarjo, (2008). counseling peers (peer counseling) to develop adolescent resilience. Department of Educational Psychology and Guidance, Faculty of Education, University of Indonesia, Jakarta.

Tegeg et al, (2008). Reproductive health knowledge and attitude among adolescents. Elsefier J.

Xiaohui Gao1., Yu Wu1., Yu Zhang1, 2012. Effectiveness of School - based Education on HIV / AIDS Knowledge, Attitude, and Behavior among Secondary School Student in Wuhan China ". OpenAccess Free. Available Online 7. 